\title{
Adamantinoma of Tibia
}

\author{
Col S Satyanarayana ${ }^{*}$, Lt Col KZ Jawed ${ }^{+}$, Maj D Sirohi", Brig J Sikdar AvSM, vSM (Retd) ${ }^{* *}$
}

MJAFI 2002; 58 : 348-349

Key Words : Adamantinoma; Locally aggressive; Tumour

\section{Introduction}

A damantinoma has been placed in the category of tumours of uncertain origin [1] due to its controversial histogenesis. The term adamantinoma has been coined due to the resemblance of the histology to ameloblastoma of the jaws. It is a rare tumour [1-3], occurring primarily in young males between 10-30 years of age. Patients usually present with a firm, slowly enlarging mass, that produces minimal disability. However, it can present rarely as a painful swelling or as pathological fracture. The commonest site in the long bones is tibia $[1,2]$. We present a case of adamantinoma in tibia in a 53 year old male.

\section{Case Report}

A 53 year old male presented with a swelling of left upper leg which he noticed 3 months ago. X-ray left leg showed a well defined radiolucent lesion involving the diaphysis of the tibia with cortical sclerosis (Fig - 1). En bloc excision of the lesion was done. Gross examination of the specimen showed a bony hard mass measuring $5 \times 3 \times 2 \mathrm{~cm}$ size. Cut surface revealed a firm, homogeneous whitish mass filling and expanding the medullary cavity. Microscopy showed extensive areas of fibrous stroma with cell

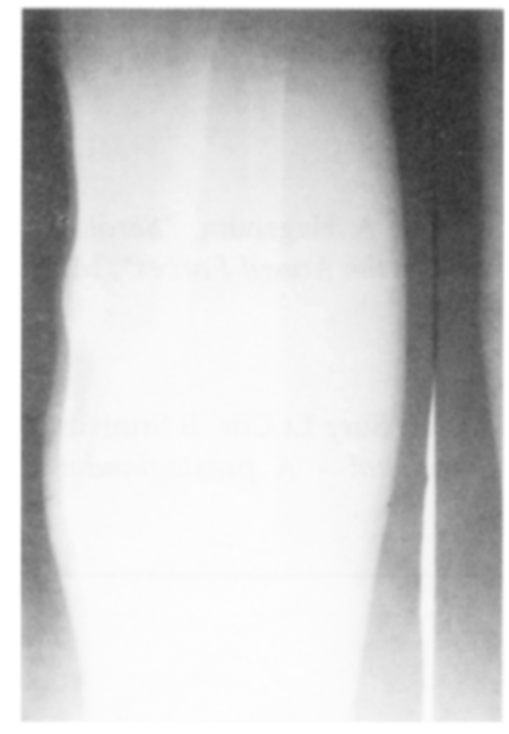

Fig. I : X-ray of leg showing lucent area with peripheral sclerosis in Tibial diaphysis nests. Cells were oval to spindle with peripheral pallisading. Central areas showed stellate reticular pattern. Focal areas of squamous differentiation with definite intercellular bridges were seen (Fig-2). Few interspersed bony spicules and focal scattered lymphocytes were seen. No a typia or mitotic activity was present. Epithelial cells showed cytokeratin positivity and stromal cells showed positivity for vimentin and smooth muscle actin. Patient is symptom free after $\mathbf{2 0}$ months of surgery.

\section{Discussion}

Adamantinoma is a tumour of controversial origin [4-6]. It is a low-grade, locally aggressive and rarely metastasizing [2,7] primary tumour of long bones. Tibial diaphysis is the commonest site in the long bones [1-3]. Other long bones involved less frequently are humerus, femur, fibula, ribs and radius. It may appear as a central or eccentric, multilocular, expansile or sharply or poorly delineated osteolytic lesion. The classical radiological finding is an area of lucency surrounded by sclerosis usually involving the cortex and rarely the medullary cavity [1]. The histogenesis of this tumour has been controversial [4-6]. Evidence now points out that developmental, epithelial cell rests differentiate into tumour. However, it is not clear as to how and why the epithelial cell rests occur in the bony contex. Key histological feature is the presence

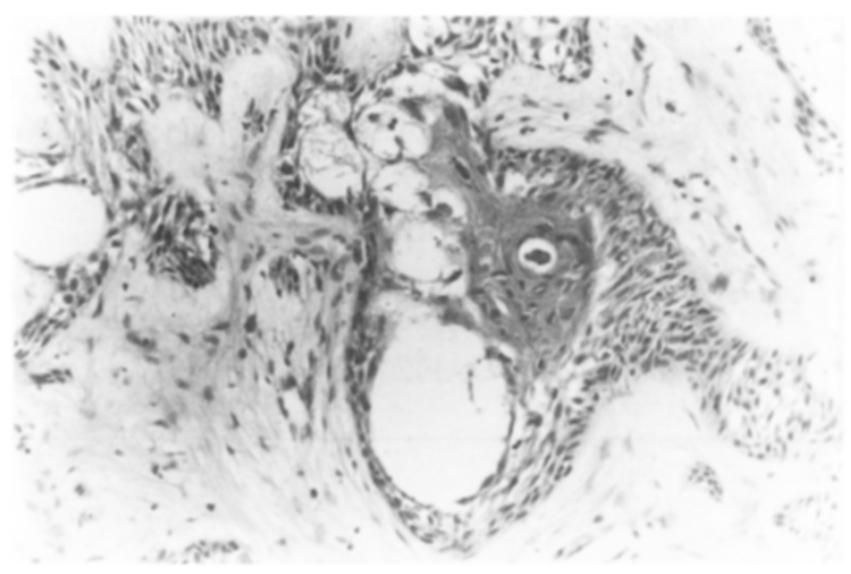

Fig. 2: Microphotograph showing epithelial cell clusters with peripheral pallisading and squamous differentation in fibrous stroma $\times 200$

\footnotetext{
"Associate Professor, Department of Pathology, Armed Forces Medical College, Pune - $411040,{ }^{+}$Classified Specialist (Pathology), Military Hospital, Jhansi, "Medical Officer (Pathology), 92 Base Hospital, C/o 56 APO," Ex-Consultant (Surgery and Orthopaedics), Base Hospital, Delhi Cantt-I10010.
} 
of epithelial cells with minimal nuclear atypia, embedded in fibrous stroma. Epithelial element is considered to be the malignant element and the fibrous part is reported to be the benign reparative process [9]. Four distinct cell patterns of spindle, basaloid, squamoid and tubular are seen [10]. The ill defined distinction between the epithelial and fibrous components led to the assumption that it is derived from a mesenchymal stem cell. Huvos and Marcove suggested an angioblastic origin [4] while other studies suggest an epithelial origin due to the cytokeratin expression $[2,5,6,10]$. Association of osteofibrous dysplasia with adamnatinoma is known for long [6] and it is felt that it is a potential precursor to this lesion [10]. Typical squamous differentiation is rare as seen in this case [2]. Abundant epithelial component points to a benign behaviour. Age of presentation is also unusual in this case as it is seen usually in younger individuals though a few cases in the elderly are also reported. Metastases to lungs, liver and to lymph nodes are reported. Smooth-muscle actin positivity found in this case has not been mentioned in literature. Metastatic carcinoma which can also be considered in the differential diagnosis should be excluded by absence of atypia, high mitotic activity and classical bi-phasic pattern of epithelial cells intermingled with fibrous stroma. Marginal resection of the tumour can have delayed local recurrence but en bloc resection is the treatment of choice [3], while Huvos and Marcove feel that amputation is better than en bloc resection [4]. Patient is free from disease after one and half years of followup. This case is reported due to the controversies surrounding this rare primary bone tumour.

\section{References}

1. Unni KK, Inwards CY. Tumors of the osteoarticular system. In : Fletcher CDM, editor. Diagnostic histopathology of tomors. $1^{\text {st }}$ ed. Edinburgh : Churchill Livingstone. 1995:1 1302.

2. Mirra JM, editor. Bone tumors diagnosis and treatment 1980. Philadelphia : JB Lippincott company, 440-8.

3. Keeney GL, Unni KK, Beabout JW. Pritchard DJ. Adarnantinoma of long bones. A clinicopathologic study of 85 cases. Cancer 1989; I:64(3)730-7.

4. Huvos AG, Marcove RC. Adamantinoma of long bones. A clinicopathological study of fourteen cases with vascular origin suggested. J Bone Joint Surg Am 1975;57(2): 148-54.

5. Rosai J. Adamantinoma of tibia : Electron microscopic evidence of its epithelial origin. Am J Clin Pathol 1969;51:78692.

6. Rosai J, Pinkus GS. Immunohistochemical demonstration of epithelial differentiation on adamantinoma of the tibia. Am J Surg Pathol 1982:6:427-34.

7. Weiss SW. Dorfman HD. Adarnantinoma of long bones. An analysis of nine new cases with emphasis on metastasizing lesions and fibrous dysplasia-like changes. Human Pathol 1997;8(2):141-53.

8. Boove JV, Van den Brock LJ, de Boer WI, Hongendoom Pc. Expression of growth factors and their receptors in adamantinoma of long bones and the implication for its histogenesis. J Pathol 1998;184(1):24-30.

9. Companacci M, Guinti A, Bertoni F, Laus M, Gitelis S. Adamantinoma of the long bones. The experience at the lstituto Ortopedico Rizzoli. Am J Surg Pathol 1981;5(6):53342.

10. Benassi MS, Campanacci L, Gamberi G, et al. Cytokeratin expression and distribution in adamantinoma of the long bones and osteofibrous dysplasia of tibia and fibula. An immunohistochemical study correlated to histogenesis. Histopathology 1994;25(1):71-6.

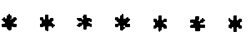

In Philosophy

Socrates said that one must marry at all costs, for in case you have a good marriage you will be a very happy man and in case you have a bad marriage, you will become a successful philosopher.

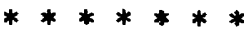

4 year old boy to his daddy - I have decided to marry.

Dad jocularly - Yeah, who do you have in mind?

Boy - Grandmother.

Daddy - Oh! how can you marry my mother?

Boy - How did you marry mine? 